\title{
Research on Distribution of Spontaneous Combustion "Three Zones" and Methane Concentration Variation before and after Nitrogen Injection in Goaf
}

\author{
Wang Jun $^{1, a}$, Liu Xianfeng ${ }^{2, b^{*}}$, Meng Yangyang ${ }^{3, c}$, Sun Fangfang ${ }^{4, d}$, \\ Huang Jinxin ${ }^{5, e}$ \\ ${ }^{1}$ CCTEG ShengyangResearch Institute,Shenyang 110016, P.R. China; \\ ${ }^{2}$ School of Resource and Safety Engineering, China University of Ming \& \\ Technology(Beijing),Beijing 100083, P.R. China; \\ ${ }^{3}$ State Key Laboratory of Coal Resource and Safe Ming, Beijing 100083, P.R. China;

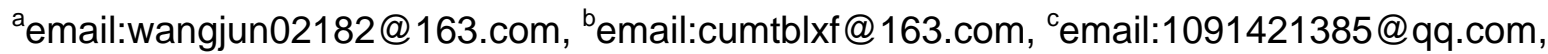 \\ demail:1017849978@qq.com, eemail:846150793@qq.com
}

\begin{abstract}
Keywords: beam tube pavement and monitor, division of "Three Zones"; explosion and combustion zone; nitrogen injection
\end{abstract}

\begin{abstract}
In the mining process of 4405 working face, spontaneous combustion of remaining coal is prevented by injecting nitrogen to goaf through buring pipe and continuous injecting nitrogen. Meanwhile, pre-bury beam tubes in the goaf and measure the gas concentration of each measuring point before and after continuous nitrogen injection. Combined with residual coal spontaneous combustion theory in goaf, the distribution variations of "Three Zones"ofgoaf spontaneous combustion were achieved. The safety zone before nitrogen injection was analyzed, explosion and combustion zone were eliminated by nitrogen injection and safetyproduction was ensured.
\end{abstract}

\section{Introduction}

A lot of loose residual coal is left in the goaf which is easy to have oxidizing reaction with oxygen in the air leakage seepage. That results in the occurrence of goaf spontaneous combustion fire and a serious threat to the mine production [1-3].At present, nitrogen injection is one of the effective measures to prevent the spontaneous combustion in the goaf of fully-mechanized caving face. Analyzing goaf's gas concentration distribution and taking corresponding measures become the reasonable means in goaf governance [4-7]. In literature 8, based on theory of gravity fluid and injection fluid, the mechanism and characters of laminar gas layer and turbulent gas layer in closed fire area were analyzed.Then the critical inert injection velocity that prevent the closed fire area from exploding was deduced and validated. Dangers and critical parameters of inert gas injection in closed fire area were verified by experiments. In literature 9, nitrogen fixation of three-phase foam and its inertingcharacteristicswere studied.The results obtained from the experiment and the practical applications indicate that the three-phase foam has a good inerting effect. It can remain the nit rogen within the water slurry, enhance the long-standing inerting effect of fire area. It can be also applied to inert fire zone with air leakage. Using Fluent(a CFD software) to do numerical simulation and build math model, DuanYulong and others studied the methane distribution law of closed fire zone when pumping inert gas. The result shows that umping velocity has great effect on methane distribution, and it is also one of the main factors causing secondary gas accident in pumping inert gas[10].

As the maturity of nitrogen injection process, technology and equipment, the application of nitrogen injection fire-fighting technology will be more extensive.Beam tube laying was adopted in the Hongyan Coal Mine to study gas distribution in goaf, and on this basis, the method of nitrogen injection was adopted to inert goaf gas and achieve the goal of safety mining. 


\section{Underground sampling tube monitoring system arrangement}

Before the tube monitoring system was set up, underground goaf gas sampling tube device can be installed to monitor gas changes, which can be operated by human, sampled back and forth, sent to the ground and do the chromatograph analysis.The specific practice was: established underground pumping station in return airflow roadway $300 \mathrm{~m}$ away from the cutting hole.

Driven by explosion-proof electric motor, air pump provide aerodynamic force to the underground sampling tube system. The 8-core cluster beam tube was paved along the air return way of working face. The tubes are put into 2 protective steel pipe, which are buried in the rear of conveyor after the cutting hole. An air intake was set up each $20 \sim 50 \mathrm{~m}$, beam tubes are centralized to the beam pipe gas extraction pumping station. Each of them is set up with ventilation valves and gas analysis were taken. Samplers are arranged equally by face's length, generally at least 5.Samplers are connected with the single beam tube to extract gas samples at different locations. Protection pipes are also needed to put on the single beam tube. When goaf gas is monitored, air bags can be adopted to take samples. Extracted by air pump, gas samples in different monitoring sites are taken to the ground for analysis. Monitor diagram of sampling beam tube underground is shown in Fig.1.

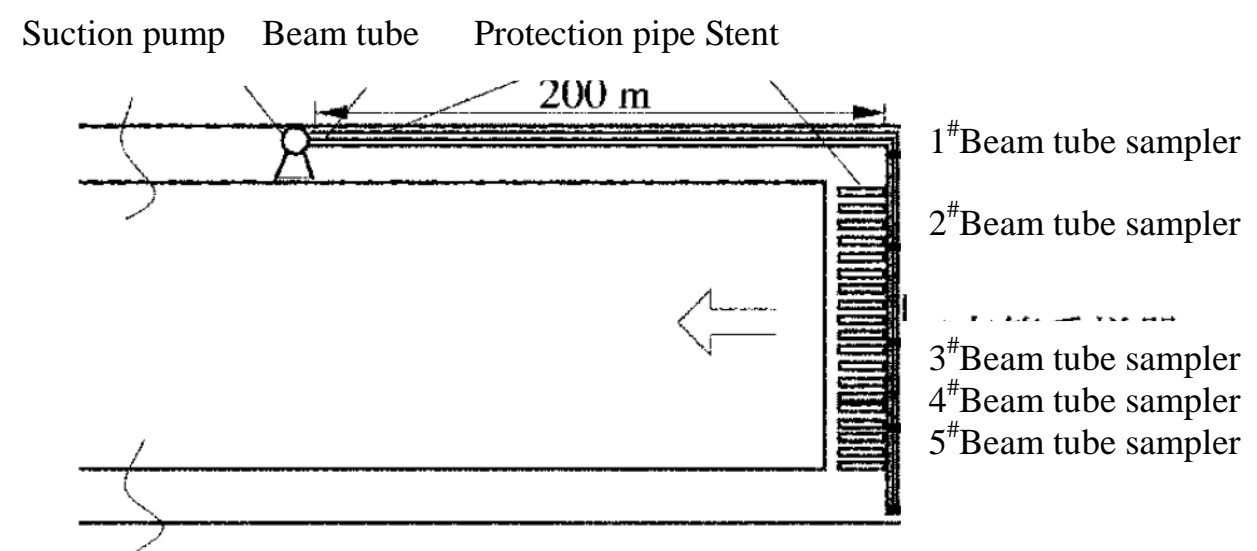

Fig.1 Monitor diagram of sampling beam tube underground

\section{2 .Gas distribution of goaf in $\mathbf{4 4 0 5}$ working face before nitrogen injection}

1)CH4 concentration is low outside and high inside, low in the lower part and high in the upper part of goaf.. $\mathrm{O} 2$ concentration is high outside and low inside. Along the advancing direction of working face,goaf gas concentrations increased with different amplitudes, showing clear zonation.

2) According to the monitoring results ofthe 5 \# mouth of the tube 4405 and formal monitoring data of working face, and principles of goaf management to point with the governance, the maximum concentration points is for the actual value of the region and the analysis is on the working face from $30 \sim 100 \mathrm{~m}$ range. $\mathrm{CH} 4$ concentration from the mined-out area presents generally upward trend with a substantially increasing working distance. Within $30 \sim 65 \mathrm{~m}$ away from working face, $\mathrm{CH} 4$ concentration in goaf rises rapidly from the beginning of the $1 \%$ to $5.21 \%$, It become basically stable at $7 \% \sim 8 \%$ to $100 \mathrm{~m}$. Towards the strike direction of $100 \mathrm{~m}$,the variation trend of average gas concentration can be described by line $y=0.0636 x-0.1733$. That is, the depth of goaf increases $1 \mathrm{~m}$, the average gas concentration in goaf increase $0.0636 \%$.

3)Along the inclination direction, the gas concentration close to the inlet side is lower. While the coal gas concentration near the upper and lower boundary wall of the mining area is generally higher. Within the range of about $0 \sim 100 \mathrm{~m}$ before the injection of nitrogen, O2 concentration of mining goaf ranges between $21 \% \sim 19.8 \%$. Its distribution rule is substantially opposite to CH4's, that is, where the concentrations of $\mathrm{CH} 4$ is high, the concentrations of $\mathrm{O} 2$ is low.

4) When the distance between goaf and coal face surpasses the $55 \mathrm{~m}$ range, $\mathrm{CH} 4$ concentration is over 5\%, and $\mathrm{O} 2$ concentration is within 19.8\% 21\%. In this case, gas explosion requirement is met. However, in consideration of the complexity of gas concentration distribution in goaf and the 
diversity of influencing factors, a certain safety coefficient should be reserved. In previous experience, a $10 \mathrm{~m}$ safety distance is adopted since safety area is defined as within a $45 \mathrm{~m}$ range between goaf and coal face. In other words, the area beyond $45 \mathrm{~m}$ range is called a explosion or burning zone.

5)Because gas follows floating rules, concentration difference occurs in perpendicular height. Gas condition, especially the concentration difference in the same exit but different height in pipeline, should be taken into consideration at level of caving zone. It is noticed that gas concentration is distinct and tends to be higher in the higher one of two beam tubes, extracted out of the $4 \#$ exit from pipelines in crossheading. On the vertical dimension, gas concentration from floor to roof correspondences to $y=1.1743 x+1.0156$, R2=0.9954, as shown in Fig.2..

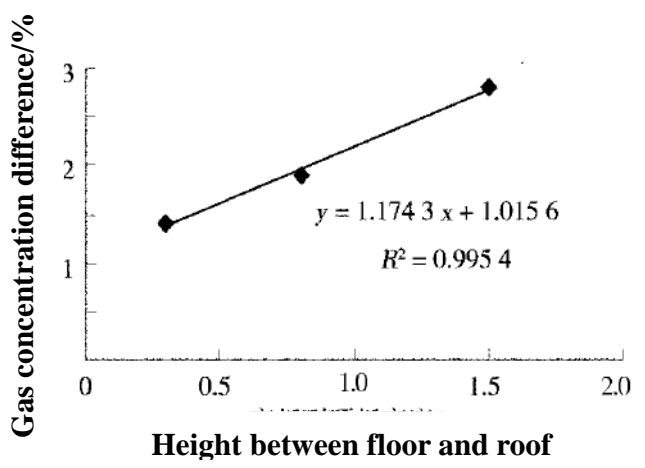

Fig.2 Gas concentration difference between floor and roof

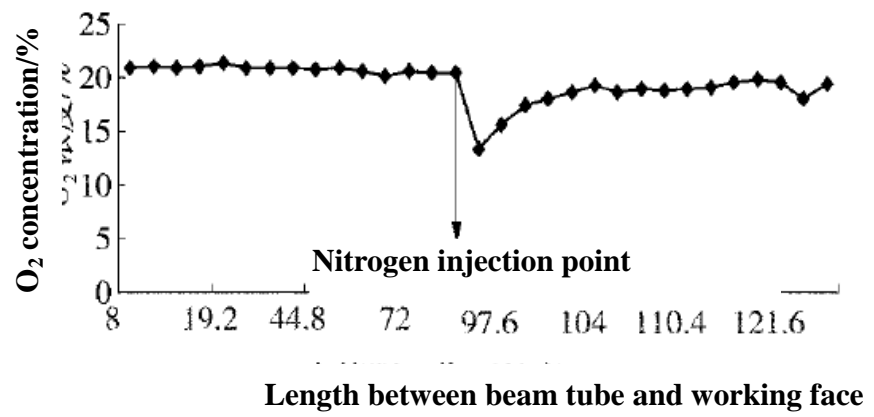

Fig.3 Concentration changing curve of $\mathrm{O}_{2}$ in 3 \# tube probe in 4405 goaf

\section{Gas Distribution Rules in the goaf after Nitrogen Injection}

After nitrogen injection, the gas in the goaf is inerted. $\mathrm{O} 2$ reduced significantly, as shown in Figure 3 and the concentration of $\mathrm{C} 2 \mathrm{H} 4$ also slightly decreases, as shown in Fig.4, Fig.5.The nitrogen injection has changed the "Three Zones" division.

\section{Analysis of "Three Zones" Impact after Nitrogen Injection}

As a high risk area of underground spontaneous combustion and gas explosion,the goaf always has a lot of potential safety problems.So the prevention of spontaneous combustion in the goaf becomes the priority of integrated control of underground spontaneous combustion.

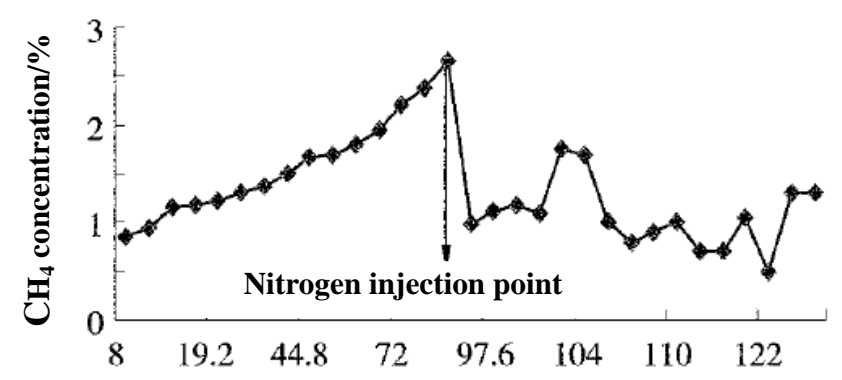

Length between beam tube and working face

Fig.4 Distributioncurveof gas concentration along the Trend of 1 \# tube mouth of goaf 4405 


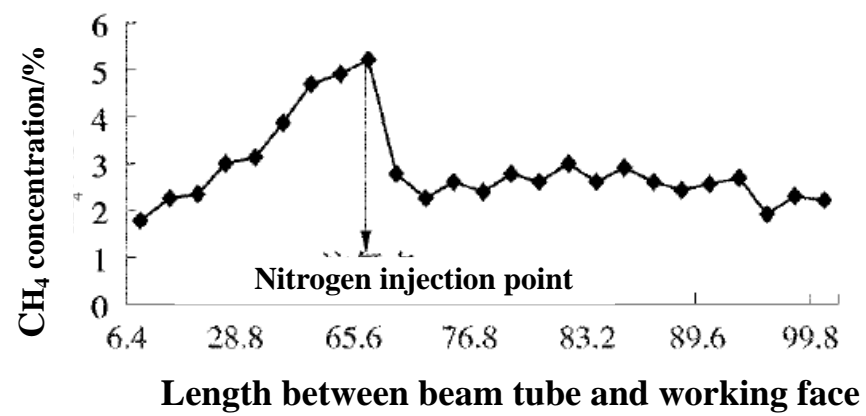

Fig.5 Distributioncurveof gas concentration along the trend of 5 \# tube mouth of goaf 4405

The distributionrange of "Three Zones" is the main technical basis of nitrogen injection in goaf and leakage blocking. It can also be the important reference of determining the reasonable advance rate. So, the testing and classification of "Three Zones" is one of the main basis content of Disaster prevention in goaf.

After nitrogen injection, the "Three Zones" of mined-out area naturally moved forward in the direction of working face. The concentration of $\mathrm{O} 2$ along the working face falls faster than that before the nitrogen injection. The effect of the nitrogen injection to the concentration of $\mathrm{O} 2$ is larger in the goaf where apart from the coal face more than 100m.Thegreatly decreasing width of oxidation zone and the depressing gas concentration reduce the possibility of spontaneous combustion and gas explosion in goaftoagreatextent. Because there is no monitoring data of the condition that the $\mathrm{O} 2$ concentration drops below the critical oxygen concentration being seen from the detected data, combining the actual experience that the minimum oxygen concentration is $9.0669 \%$, the oxidation zone of the 4405 working face is more than $80 \mathrm{~m}$, and the suffocation zone should be above $200 \mathrm{~m}$.

\section{Division of explosion combustion area}

According to explosion combustion goaf area, the mined-out area can be divided into "Three Area”, namely the security area, explosion area, combustion area. Based on the actual monitoring data of 4405 and formal experience, before nitrogen injection, the safety area range within $0 \sim 45$ m,explosion area range within $45 \sim 200$ m,combustion zone is $200 \mathrm{~m}$ away. The appearance of explosion combustion is eliminated after optimization of nitrogen injection. Because of no obvious spontaneous combustion phenomenon, the mined-out area is basically in a stable condition.

\section{Conclusions}

(1) By laying tube to monitor the gas of mined-out area, the distribution of goaf gas is obtained. After adopting continuous nitrogen injection, thewidth of oxidation zone decreases greatly and the gas in the goaf is preferably inerted.

(2) Bycontrasting the goaf gas before and after nitrogen injection, the change of "three zones" of goaf is analyzed, which provide reliable security for high yield and high efficiency of fully-mechanized caving face.

\section{Reference}

[1] Schma Dick, Duyzer Jan H, VenHeven, etal.Model for the Spontaneous Heating of Coal[J].Fuel,1985,64(7):963-972.

[2] Brooks Kevin, SvanasNicoloas, Glasser David. Evaluating the Risk of Spontaneous Combustion in Coal Stockpiles[J].Fuel,1988,67(5):651-656.

[3] XuJingcai, Zhang Xinhai, Deng Jun, etal. Study on three zones of mined out area and spontaneous combustion danger of workface 2106 in Changcun Coal Mine[J].Journal of Hunan 
University of Science and Technology( Natural Science Edition),2004,19( 3) :1-499(In Chinese).

[4] HaoYu,LiuJie, Wang Changyuan, etal. Application of feeding nitrogen in extra-thick coal seam of comprehensive mechanized and breaking props coal mining[J].Safety in Coal Mines,2008( 7):41 -43(In Chinese).

[5] Wang Junfeng, Li Youzhong. Examination of gas change and distribution of thriple stripe at the goaf while injecting nitrogen[J].Journal of Taiyuan University of Technology,2000,31(6):638641(In Chinese).

[6]Sun Chundong,Li Zhantao,Chen Li,et al. Inert technology application for fire treatment in dead end referred to high gassy mine[J]. Procedia Engineering,2011,26:712-716(In Chinese).

[7]Wang Haiyan, Feng Chao, Wangzhongwen, at el. Dangers and critical parameters of inert gas injection during mine fire sealing[J]. Journal of China Coal Society,2014,39(S1):117-122(In Chinese).

[8]Zhou Fubao, Wang Deming, Zhang Yuliang, at el.Nitrogen Fixation of Three-Phase Foam and Its Inert ing Properties[J]. Journal of China University of Mining \& $\mathrm{T}$ echnology,2006,35(1):11-14(In Chinese).

[9]DaunYulong, Zhou Xinquan, Ding Xiaolei, at el. The methane distribution law of closed fire zone when pumping inert gas[J]. Journal of China Coal Society,2010,35(1):80-84(In Chinese).

[10]Li Zongxiang, Li Haiyang, JiaJinzhang. Numerical simulation of preventing spontaneous combustion by nitrogen injection in goaf of Y-type ventilation face(In Chinese). 